\title{
The Key to the Cardiovascular Diseases Situation Improvement in Conditions of North-West Region of Russia
}

\author{
Boris Fishman ${ }^{1,}$, Victor Veber $^{1}$, Mikhail Yukhno ${ }^{2}$, Oksana Lole $^{2}$, Violetta Kostyrkina ${ }^{1}$, \\ Anton Dovgal ${ }^{2}$, Pavel Starikov ${ }^{2}$, Irina Prozorova ${ }^{2}$ \\ ${ }^{1}$ Department of Internal Diseases, Yaroslav-The-Wise Novgorod State University, Veliky Novgorod, Russia \\ ${ }^{2 " C e n t r a l ~ C l i n i c a l ~ H o s p i t a l ", ~ V e l i k y ~ N o v g o r o d, ~ R u s s i a ~}$ \\ Email address: \\ Fishman@mxc.ru (B. Fishman) \\ ${ }^{*}$ Corresponding author
}

\section{To cite this article:}

Boris Fishman, Victor Veber, Mikhail Yukhno, Oksana Lole, Violetta Kostyrkina, Anton Dovgal, Pavel Starikov, Irina Prozorova. The Key to the Cardiovascular Diseases Situation Improvement in Conditions of North-West Region of Russia. Cardiology and Cardiovascular Research. Vol. 2, No. 1, 2018, pp. 8-14. doi: 10.11648/j.ccr.20180201.13

Received: January 18, 2018; Accepted: February 9, 2018; Published: March 28, 2018

\begin{abstract}
The purpose of research - studying patients' adherence of arterial hypertension and ischemic illness of heart to treatment in conditions of Northwest region of Russia. In the period from 2012 to 2013 by analogy with a "Regular Treatment and Prevention as the Key to Improving CVD Situation in Russia - RELIEF" large-scale study on assessing patients adherence to doctor's recommendations was conducted. The study analyzed the factors that have more or less significant impact on the quality of treatment and the adherence to treatment of hypertension and CHD. Assessment of adherence to treatment of patients is given according to data received from 28 district doctors/general practitioners who have included 78 patients with proven hypertension/CHD. Analysis of the received data is performed with the help of Program Statistica 10, Stat Soft. There is insufficient awareness among respondents about risk factors and disease outcome. A radical change has been proposed for principles of preventive care for patients, taking into account all the prevention elements for hypertension/CHD in cardiac treatment centers or preventive medicine and rehabilitation centers, with creating dynamic active register of patients with hypertension/CHD and related complications.
\end{abstract}

Keywords: Adherance to Treatment, Hypertension/CHD Patients, Regional Study

\section{Introduction}

According to the World Health Organization (WHO) definition, adherence to treatment is the degree of a person's behavior (regarding to prescribed medicine taking, diet and / or other lifestyle changes) consistency with a doctor or health care provider recommendations [1-3].

The results of large-scale controlled researches indicate that the treatment of patients with arterial hypertension $(\mathrm{AH})$ and coronary heart disease (CHD), in compliance with principles set by international and domestic experts, allows to achieve a good clinical effect, a significant reduction of cardiovascular complications rate, as well as disability and mortality index [4-9].

The gap between controlled clinical researches and actual clinical practice results is due to a number of socioeconomic and medical reasons. Among them, the decisive factor is the low adherence of patients to doctors' recommendations, both drug and non-pharmacological [10-15], as in recent years the low adherence to treatment of hypertension is regarded by an increasing number of experts as an independent risk factor for development of cerebrovascular diseases, cerebral strokes in particular, and low adherence to the treatment of IHD, as a risk factor for adverse outcomes and death [16].

Taking into account the foregoing, by analogy with the Federal research "Regular Treatment and Prevention, the Key to Improving the Situation of Cardiovascular Diseases in Russia - RELIF" [17], a research of patients adherence with $\mathrm{AH} / \mathrm{CHD}$ to medical recommendations was conducted in 2012-2013 in the Novgorod Region.

The Novgorod region is among the regions with high mortality rate from cardiovascular pathology. The causes of 
population high mortality rate became the ground for conducting a special research, with an emphasis on studying the reasons of adherence to treatment among the respondents with $\mathrm{AH} / \mathrm{CHD}$ (Figure 1).

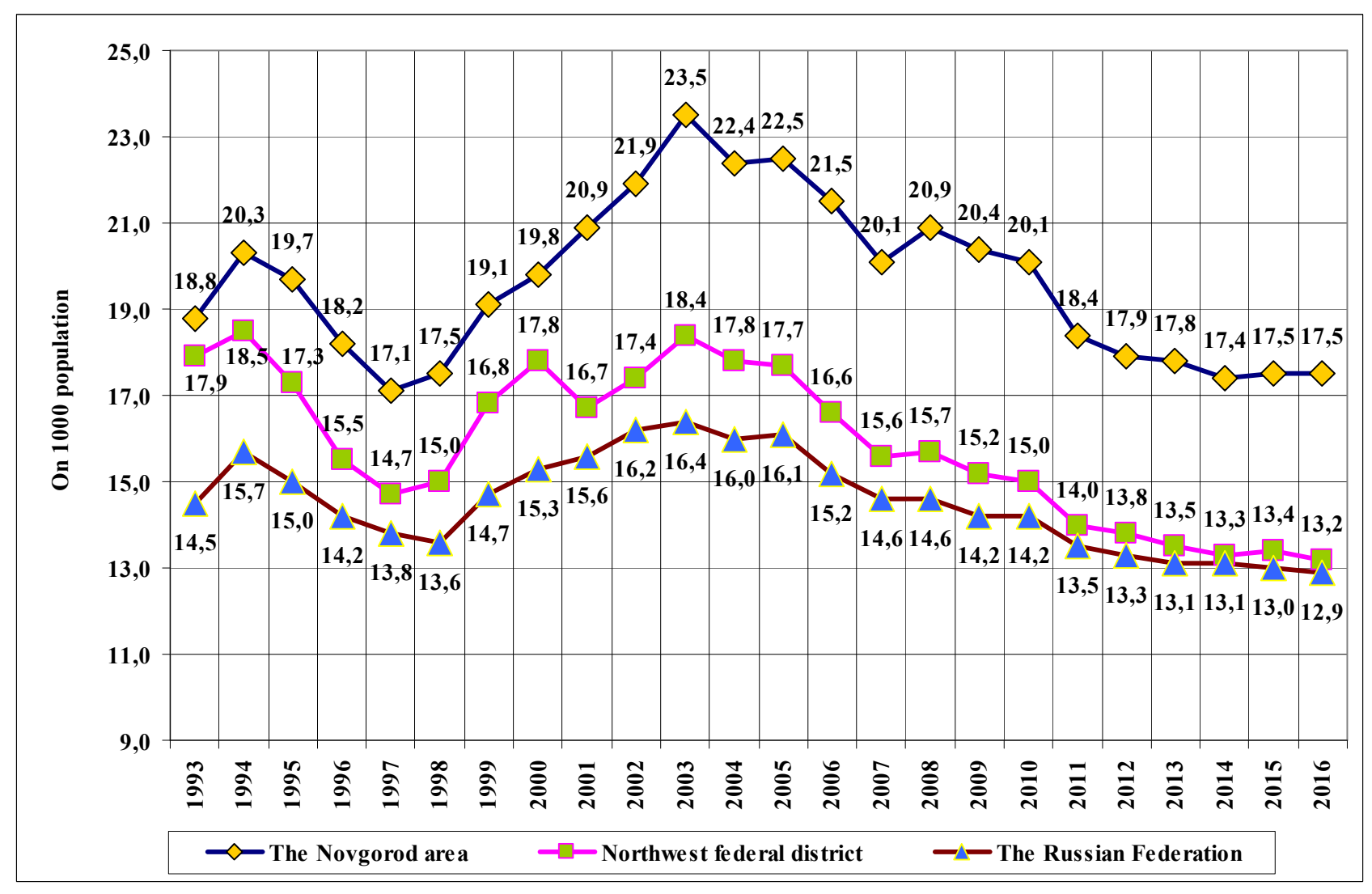

Figure 1. Characteristics of the overall mortality rate dynamics among the population.

In 2016 the percentage of deaths from cardiovascular pathology was $59.6 \%$ of the total number of deceased.

The objective of the research is to study the adherence of patients with arterial hypertension and coronary heart disease to treatment in the North-West region of Russia conditions.

\section{Methods}

According to the protocol, in 2012-2013 in each polyclinic in Veliky Novgorod 7 district doctors (general practitioners) who worked full time in this position, were randomly included in the research during. The choice of the doctor was accidental and was limited only by the doctor refusal to participate in the research. The doctor, agreed to participate, consistently within one working day included at least 10 patients with hypertension and / or coronary heart disease, who came to receive the treatment and who meet the inclusion criteria.

The analytical material included data from 28 district doctors / general practitioners who included 78 patients with verified AH and / or CHD in the research.

The patient's adherence to treatment was evaluated according to the answer to the following question: "Do you take recommended medicine regularly?" According to experts recommendations [3], the positive answer to this question was checked by the patient's agreement with three statements: "I take the medicine every day", "I do not miss a single dose", "I strictly take the doses of the medicine as recommended by the doctor". In the case of irregular therapy, the patient indicated the reasons of it.

The patient also filled in the Hospital Anxiety and Depression Scale (HADS) [18-21].

The obtained data processing was carried out using the parametric and nonparametric statistics criteria. The data was grouped according to the variational series, taking into consideration the significance of the results for $\mathrm{p}<0.05$ in $\mathrm{t}$ values of the Student with allowance for the Bonferroni correction, the Gaussian density was used for the scattering characteristics by the interquartile range - $\mathrm{QR}$ as a robust dispersion analog $(\mathrm{E} 0.25,0.75=\mathrm{X} 0.75-0.25)$ with compulsory calculation of the "emissions" presence. We used cluster and factor analyzes to determine the rank and the relationship between the obtained characteristics from multidimensional methods. The correlation degree between the individual characteristics was determined with Spearman rank correlation coefficient. Statistical data processing was performed by the means of Statistical software StatSoft Statistica, version 10 .

\section{Results.}

The social status of patients. To evaluate the social status of 
patients with arterial hypertension and coronary heart disease, 22 women and 56 men were included in the number of patients. The average age for women was 57.4 and for men 65.4 .
Parametric data characterizing the risk factors of respondents, according to the Federal Research "RELIF", presented in Table 1.

Table 1. Risk factors characteristics of parameters of respondents, considering to gender.

\begin{tabular}{|c|c|c|c|c|c|c|c|}
\hline \multirow{2}{*}{ Factor } & & \multicolumn{2}{|c|}{ Female } & \multicolumn{2}{|l|}{ Male } & \multirow{2}{*}{$\mathbf{t}$} & \multirow{2}{*}{$\mathbf{P}$} \\
\hline & & M & $\mathbf{M} \pm \mathbf{S D}$ & M & $\mathbf{M} \pm$ SD & & \\
\hline \multirow{5}{*}{ Marital status } & Single & 18.0 & $24.9 \pm 15.9$ & 15.9 & $21.9 \pm 14.2$ & 0.16 & 0.871 \\
\hline & Married & 54.3 & $22.6 \pm 20.0$ & 56.6 & $20.5 \pm 16.3$ & -0.20 & 0.842 \\
\hline & Divorced & 3.4 & $2.9 \pm 2.3$ & 3.7 & $2.2 \pm 1.8$ & -0.17 & 0.866 \\
\hline & Lives with a permanent partner & 1.6 & $1.6 \pm 1.2$ & 1.2 & $0.9 \pm 0.7$ & 0.54 & 0.597 \\
\hline & Widow (widower) & 19.3 & $24.7 \pm 20.1$ & 14.8 & $23.2 \pm 18.9$ & 0.35 & 0.733 \\
\hline Children & None & 0.3 & $0.5 \pm 0.3$ & 0.4 & $0.6 \pm 0.4$ & -0.37 & 0.718 \\
\hline \multirow{4}{*}{ Education } & Secondary & 29.9 & $9.8 \pm 8.3$ & 31.3 & $8.2 \pm 6.8$ & -0.30 & 0.769 \\
\hline & Specialized secondary & 36.4 & $8.6 \pm 6.1$ & 38.2 & $6.8 \pm 5.3$ & -0.43 & 0.676 \\
\hline & Incomplete higher education & 6.3 & $8.0 \pm 5.3$ & 5.8 & $6.3 \pm 4.1$ & 0.15 & 0.885 \\
\hline & Higher education & 22.2 & $9.5 \pm 8.3$ & 17.7 & $6.5 \pm 5.0$ & 1.04 & 0.319 \\
\hline \multirow{2}{*}{ Working } & Yes & 49.7 & $34.2 \pm 28.7$ & 48.8 & $38.1 \pm 34.0$ & 0.04 & 0.965 \\
\hline & No & 45.2 & $33.1 \pm 28.0$ & 45.8 & $36.9 \pm 31.1$ & -0.03 & 0.974 \\
\hline Non-working & According to the age & 26.1 & $28.4 \pm 25.6$ & 29.0 & $37.3 \pm 32.0$ & -0.17 & 0.87 \\
\hline \multicolumn{2}{|l|}{ Disability in the age of } & 41.1 & $21.5 \pm 17.7$ & 44.9 & $19.1 \pm 14.4$ & -0.35 & 0.7348 \\
\hline \multicolumn{2}{|c|}{ Polyclinical visits (number of times) } & 2.4 & $0.7 \pm 0.6$ & 2.7 & $0.6 \pm 0.4$ & -0.76 & 0.4602 \\
\hline \multicolumn{2}{|c|}{ Hospitalization (number of times) } & 0.9 & $0.3 \pm 0.3$ & 1.1 & $0.4 \pm 0.3$ & -1.07 & 0.3064 \\
\hline \multirow{3}{*}{ Diet } & keeps to & 40.2 & $2.8 \pm 2.2$ & 28.9 & $3.0 \pm 2.2$ & 7.27 & 0.0001 \\
\hline & Do not keep to & 55.0 & $3.4 \pm 2.9$ & 65.4 & $9.2 \pm 6.7$ & -2.82 & 0.015 \\
\hline & Never smoked & 62.4 & $11.1 \pm 8.2$ & 33.2 & $11.2 \pm 8.6$ & 4.91 & 0.0004 \\
\hline \multirow{3}{*}{ Smoking } & Quited smoking & 14.1 & $8.5 \pm 6.3$ & 25.8 & $13.4 \pm 10.7$ & -1.94 & 0.075 \\
\hline & Smokes & 31.9 & $39.2 \pm 24.6$ & 36.8 & $19.9 \pm 16.8$ & -0.29 & 0.774 \\
\hline & Number of cigarettes per day & 8.4 & $5.2 \pm 3.3$ & 20.2 & $23.1 \pm 14.7$ & -1.32 & 0.212 \\
\hline Duration of smoking & & 12.1 & $10.1 \pm 7.4$ & 34.7 & $50.2 \pm 33.1$ & -1.17 & 0.265 \\
\hline & Every day & 2.6 & $2.4 \pm 2.0$ & 22.2 & $10.8 \pm 8.9$ & 0.86 & 0.407 \\
\hline Alcohol consumption & Several times a week & 5.2 & $2.6 \pm 1.7$ & 19.7 & $3.3 \pm 2.6$ & -0.91 & 0.381 \\
\hline & Several times a month & 14.3 & $6.5 \pm 5.4$ & 19.9 & $5.0 \pm 4.0$ & -1.18 & 0.2616 \\
\hline & Several times a year & 31.4 & $6.5 \pm 5.2$ & 7.9 & $3.9 \pm 3.1$ & -0.04 & 0.9668 \\
\hline & None & 44.3 & $9.6 \pm 7.3$ & 50.3 & $12.6 \pm 10.2$ & 1.23 & 0.2423 \\
\hline Alcohol consumption & $50-100 \mathrm{ml}$ of vodka & 11.2 & $4.1 \pm 3.0$ & 13.4 & $6.2 \pm 5.0$ & -3.56 & 0.0040 \\
\hline & More than $100 \mathrm{ml}$ of vodka & 4.3 & $4.2 \pm 3.0$ & 11.9 & $3.9 \pm 3.2$ & -1.64 & 0.128 \\
\hline & None & 44.9 & $8.1 \pm 5.9$ & 22.8 & $19.9 \pm 15.7$ & -0.96 & 0.357 \\
\hline & Every day & 6.2 & $3.1 \pm 2.2$ & 56.3 & $11.6 \pm 9.0$ & 1.32 & 0.21 \\
\hline Psychoemotional & Several times a week & 16.7 & $2.4 \pm 2.0$ & 16.1 & $13.0 \pm 10.1$ & 1.12 & 0.288 \\
\hline & Several times a month & 17.1 & $4.0 \pm 3.1$ & 253.3 & $68.4 \pm 54.5$ & 1.33 & 0.207 \\
\hline & Several times a year & 11.2 & $5.2 \pm 4.1$ & 55.4 & $7.9 \pm 6.4$ & -0.27 & 0.788 \\
\hline & Restricted & 24.6 & $15.6 \pm 12.9$ & 37.7 & $5.1 \pm 3.9$ & 0.19 & 0.854 \\
\hline Physical activity & Moderate & 55.4 & $11.2 \pm 8.0$ & 20.8 & $2.5 \pm 2.1$ & -0.15 & 0.883 \\
\hline & Significant & 21.5 & $18.2 \pm 13.8$ & 19.2 & $16.1 \pm 13.7$ & 0.63 & 0.539 \\
\hline Minutes spent on walk & & 238.3 & $65.8 \pm 54.2$ & 32.9 & $20.4 \pm 18.0$ & -0.42 & 0.683 \\
\hline & Yes & 60.7 & $6.4 \pm 5.1$ & 25.9 & $18.8 \pm 16.5$ & 1.38 & 0.1913 \\
\hline Dissatisfaction with & No & 33.4 & $7.5 \pm 5.5$ & 24.2 & $16.8 \pm 14.7$ & -1.24 & 0.2377 \\
\hline material situation & $\begin{array}{l}\text { Monthly income for } 1 \text { person } \\
\text { (thousand of rubles) }\end{array}$ & 19.6 & $2.5 \pm 1.7$ & 12.4 & $2.9 \pm 1.9$ & -0.92 & 0.3780 \\
\hline Dissatisfaction with & Yes & 21.8 & $13.2 \pm 10.4$ & 31.5 & $15.2 \pm 13.2$ & 0.34 & 0.7434 \\
\hline official position & No & 35.5 & $19.8 \pm 17.5$ & 19.5 & $15.0 \pm 12.6$ & 0.24 & 0.8117 \\
\hline Dissatisfaction with & Yes & 29.8 & $17.3 \pm 15.1$ & 60.6 & $7.0 \pm 5.3$ & 0.40 & 0.6940 \\
\hline working conditions & No & 24.0 & $15.5 \pm 12.0$ & 18.4 & $4.1 \pm 3.1$ & -0.02 & 0.9838 \\
\hline & No motivation & 13.3 & $4.3 \pm 3.7$ & 6.8 & $4.4 \pm 3.8$ & -9.62 & 0.01 \\
\hline Working motivation & Moderate & 34.5 & $15.0 \pm 12.1$ & 60.3 & $20.2 \pm 16.3$ & -3.26 & 0.0069 \\
\hline (desire to work) & Expressive & 20.7 & $14.6 \pm 12.4$ & 9.4 & $4.4 \pm 3.3$ & 0.16 & 0.8753 \\
\hline & Absent & 56.8 & $6.2 \pm 4.1$ & 22.2 & $10.8 \pm 8.9$ & -1.08 & 0.3028 \\
\hline Dissatisfaction with & Moderate & 24.6 & $4.5 \pm 3.3$ & 19.7 & $3.3 \pm 2.6$ & 2.64 & 0.0217 \\
\hline family relations & Expressive & 16.6 & $28.4 \pm 18.2$ & 19.9 & $5.0 \pm 4.0$ & 0.90 & 0.3856 \\
\hline Recommended & Yes & 58.0 & $23.7 \pm 18.3$ & 7.9 & $3.9 \pm 3.1$ & -0.20 & 0.8483 \\
\hline treatment & No & 10.6 & $5.8 \pm 4.8$ & 50.3 & $12.6 \pm 10.2$ & 0.45 & 0.6637 \\
\hline
\end{tabular}


The BMI of the respondents was in one statistical range, and BMI for women was 27.9 and BMI for men was 30.0.

The patients educational qualification had its own specific characteristics. So, the incomplete secondary education was the characteristic for only $12.5 \%$ of men. The proportion of women with secondary education was statistically higher than of men and it was $22.7 \%$ (men $-14.3 \%$ ) with $\mathrm{P}<0.0027$. At the same time, the proportion of secondary special education of men was higher than of women $(\mathrm{P}<0.046)$ and it was $35.7 \%$. The incomplete higher and higher education is more typical for women. Therefore, it can be seen, that the majority of patients, regardless of gender, are characterized by having secondary or higher education. Only a small part of men have an elementary education.

The occupation of patients is mainly represented by retired persons. At the same time, $27.3 \%$ of women work as manual workers ( 3 times as many as men) and 1.3 times less often as non-manual workers. The proportion of women engaged in entrepreneurial activity is higher than of men. So, there is a direct discrepancy between the educational qualification and its realization in the profession selection, which can contribute to forming an internal conflict of patient satisfaction with the occupation.

Evolving the marital status of respondents it was noticed that $91 \%$ of women are married, while only $50 \%$ of men are married. $86.4 \%$ of women have children (only $16.1 \%$ of men have children). However, the number of children is statistically the same for both men and women. In fact, the basic cohort of single respondents is mainly represented by men.

With statistically homogeneous indicators of the disability frequency of respondents with regard to gender $(\mathrm{P}>0.05)$, the presence of disability group 3 is 2.2 times more common among women; the disability group 1 is mainly recorded within $3.6 \%$ among men. The frequency of disability group 2 does not have gender differences and is $\mathrm{QR}=31.8 \div 35.7 \%$ for $(\mathrm{P}>0.05)$, correspondingly for women and men. The frequency of disability group 2 correlates with the frequency of myocardial infarction $(r=0.89, p=0.0032)$, and the frequency of disability group 1 correlates with the consequences of a cerebral stroke.

The respondents' incomes are mainly classified as middle and comprise $68.2 \%$ for women and $46.4 \%$ for men.

Risk factors prevalence among patients. Evaluating risk factors prevalence of patients with arterial hypertension and coronary heart disease, it was found that the main part of women do not smoke (87.5\%). Despite the disease, only $7.1 \%$ of women continue to smoke. The picture is somewhat different among men. In that way, $36.4 \%$ of men never smoked or quitted smoking after diagnosis. At the same time, $27.3 \%$ of respondents continue to smoke. The duration of smoking for women is 12 years and the duration of smoking for men is 7.4 years. The number of cigarettes smoked per day for men is 14 , for women -9 .

A similar picture evaluating the alcohol consumption of respondents is observed. So, $94.6 \%$ of women and $45.5 \%$ of men do not drink alcohol. $36.4 \%$ of men drinking alcohol and only $5.4 \%$ of women drinking alcohol consume $250 \mathrm{~g}$ of vodka or 1 bottle of wine per week. $18.1 \%$ of men can be attributed to the category of alcohol abusers.

Evaluating the amount of respondents physical activity it was found that mainly respondents consider their physical activity to be optimal and only $28 \%$ of men consider their physical activity insufficient.

Thus, evaluating behavioral risk factors, one can note the existence of a high level risk among a quarter of male respondents due to high frequency of smoking and alcohol consumption and insufficient physical activity.

Within $18 \%$ of respondents, regardless of gender, the salt is added to food. $59 \%$ of women and $20 \%$ of men do not limit the fat consumption. Vegetable fat is mainly used of all the fats.

The most interesting data were obtained while estimating the fish consumption frequency. So, very rare fish consumption have from $14 \%$ (women) to $16 \%$ (men) of respondents. Later on, the frequency of fish consumption varies between $40-50 \%$.

In this way, the "food" recommendations for the respondents dyslipidemia prevention do not find the desired embodiment.

The fruit consumption frequency has no gender statistical differences and is on the scale of $30 \%$ of respondents, who consume between 200 and 400 gr. fruit per day. Noteworthy, the amount of fruit was not consumed daily. So, $23 \%$ of women and $30 \%$ of men do not consume fruits every day, and $14 \%$ of women and $9 \%$ of men consume more than 500 grams daily. The data given is significantly lower than the average data for Russia and the North-West Federal District.

As our research showed, only $9 \%$ of women and $23 \%$ of men do not consume sugar. The highest frequency of sugar consumption ( 2 lumps) is among $64 \%$ of women and $43 \%$ of men.

Estimating the knowledge level of hypertension / coronary heart disease risk factors, it was found that men identify the necessity for salt restriction $(19.6 \%)$ and women identify the necessity of weight loss, nutrition rationalization and salt restriction $(9.1 \%)$ as the most menacing risk factors. The remaining risk factors are not leading. And the recommendations received from the doctor were failed in the main part of the respondents. Thus, $44.6 \%$ of men and $31.8 \%$ of women adhered to the recommendations. Among the blood pressure increase reasons, more than $40 \%$ of respondents regardless of gender noted the presence of stress, women noted alcohol consumption and smoking. Excess body weight - as a factor of increasing blood pressure was noted by $25 \%$ of men and $13 \%$ of women. The remaining factors were not dominant.

In that way, preventive measures due to minimization of hypertension main risk factors are not widespread among the respondents.

Assessing the frequency of BP control, it was determined that $36 \%$ of women and $59 \%$ of men monitor blood pressure 
daily; and women are 2 times more likely than men $(27.3 \%$ and $12.5 \%$, respectively) to monitor blood pressure $1-2$ times a week. At the same time, BP control in case of poor health is carried out by $22.7 \%$ respondents, regardless to gender differences.

So, the data presented indicates patients lack of motivation to control blood pressure daily.

Checking the respondents knowledge of the optimal BP levels, it was found that $59.1 \%$ (women) and $42.9 \%$ (men) did not know the normal level of SBP and accordingly $22.7 \%$ and $23.2 \%$ the normal level of DBP.

At the same time, the overwhelming majority of the respondents complained of headache $(63.6 \%$ and $76.8 \%$, respectively, for women and men), men complained of nausea $(39.3 \%)$, general discomfort $(53.6 \%)$ and palpitations (46.4\%); women - of face redness $(36.4 \%)$.

Thus, the respondents - patients with AH had clearly expressed complaints, typical for $\mathrm{AH}$, and these complaints were announced only during the questioning.

The adherence to treatment of respondents characteristics. Evaluating the completeness of respondents with $\mathrm{AH}$ medicine taking frequency, it was established that only $40.9 \%$ of women and $10.7 \%$ of men take medicine regularly. Doses are adhered by $59.1 \%$ of women and $83.9 \%$ of men. Assessing reasons of missing or refusing to take medicine, it was found that $31.8 \%$ of women and $10.7 \%$ of men take medicine only in cases of blood pressure increase. The forgetfulness of medicine taking was indicated by $13.6 \%$ of women and only $5.4 \%$ of men. $4.5 \%$ of women noted the high cost of medicine. $4.5 \%$ of women - respondents independently made a decision for discrete medicine taking.

At the same time, the overwhelming majority of respondents are aware of possible hypertension complications as myocardial infarctions (42\% of men and $50 \%$ of women) and cerebral stroke $(66.1 \%$ and $63.6 \%$ of men and women, respectively). At the same time, only $4.5 \%$ of women and $3.6 \%$ of men knew of a possible fatal outcome.

The reason for this phenomenon is the lack of information from the doctor, that $\mathrm{AH}$ is a serious incurable disease and complications prevention, including fatal outcome, is only lifelong medicine taking, risk factors minimization and a constant blood pressure control.

Attitude evaluation of patients with coronary heart disease to their disease. As our research showed, respondents' opinions about the causes of the disease are gender specified. So, $39.3 \%$ of men and $22.7 \%$ of women believe that the cause of the disease is stress. The leading role of excess weight is mentioned by $26.8 \%$ of men, they also note the lifestyle (3.6\%), weather dependence (5.4\%), and hypodynamia $(8.9 \%)$ as a significant risk factor of disease development. As the main risk factors, women noted the factor of irregular treatment $(9.1 \%)$, severe physical activity (18.2\%), smoking (27.3\%), alcohol abuse $(22.7 \%)$ and malnutrition $(18.2 \%)$. The general risk factor within the statistical corridor is high blood pressure and high cholesterol. It is noteworthy that most of the respondents could not identify the main risk factors for CHD as dominant.

Assessing patient compliance, it was clarified that $77.3 \%$ of women and $82.1 \%$ of men were advised by the doctor to change the lifestyle considering the leading risk factors and only $16-22 \%$ of the respondents did not receive this advice.

The duration of disease among women averaged 13.6 years, and the duration of disease among men averaged 10.7 years. Throughout the treatment, $81.8 \%$ of women noted health deterioration in case of medicine discontinuation. At the same time, men completely did not pay attention to health changes.

Among the complications due to the medicine discontinuation, respondents noted a number of effects, which are not related to the effects of medicament. So, $9.1 \%$ of women noted the presence of cough and $4.5 \%$ of women noted dizziness and allergies. These symptoms were associated directly with the "vacation" during taking medicine. Men noted the presence of allergy $(10.5 \%)$, edema (5.4\%), headaches and weakness (1.8\%), cough (3.6\%). However, the reason for such effects was that they did not consider the medicament discontinuation. At the same time, $27.7 \%$ of women and only $3.6 \%$ of men applied for medical assistance at polyclinics and no more than $4.5 \%$ of respondents called for an ambulance.

Among the patients with coronary artery disease, only $4.5 \%$ of women had the certificate of work incapacity. $9.1 \%$ of women and $85.7 \%$ of men were hospitalized after calling for an ambulance, which indicates a high significance of fear absence or presence in case of a heart attack.

This obviously is connected with the lack of complete information on the disease among the respondents. So, half of the patients regardless of gender needs additional information.

Determining the structure of additional information, it was stated that the respondents place the information about harm of smoking and alcohol abuse on the top spot, without denying the fact of this importance, they would like to know the possibilities to quit these bad habits.

Women were also interested in the possibility of psychological stress protection and increased physical activity, and men's were interested in medicine treatment issues. Regardless of gender, respondents noted a lack of information about rational nutrition and diet therapy.

Evaluating the source of information, it was established that women receive information about the disease mainly from a district doctor or a hospital doctor; while men receive information from relatives, Internet or the media.

The listed figures indicate the availability of singlechannel information and the absence of patients informing system about the causes, risk factors and outcomes of the disease. More than $36 \%$ of women and a small number of men $(3.6 \%)$ noted their readiness to change their lifestyle when they receive additional information. However, within $40 \%$ of respondents, regardless of gender, do not intend to change anything in their lives.

Patients basically received the doctor's advice about the necessity to keep a diet, to quit smoking, to reduce physical activity, to lead a healthy lifestyle and to reduce weight. Recommendations about the necessity of regular medicine 
treatment, blood pressure control, job change, stress avoiding recommendations were received only by men.

Within $40 \%$, regardless of gender, patients received recommendations for non- medicine therapy; $66.1 \%$ of men and $40.9 \%$ of women adhered to the doctor's recommendations.

\section{Discussion and Conclusion.}

The presented results of the regional research indicates high prevalence of both social and biological risk factors of patients with $\mathrm{AH}$ and $\mathrm{CHD}$. There is also a low level of medical awareness of cardiovascular risk factors and complications among the respondents, as well as an insufficient level of blood pressure self-control of patients with hypertension. It was shown that patients with $\mathrm{AH}$ and CHD are longing for receiving additional medical information, consultations and recommendations of doctors about risk factors.

This research confirmed that a significant number of patients with $\mathrm{AH}$ and $\mathrm{CHD}$ are motivated in terms of improving their lifestyle and need a practical doctor's help to change their lifestyle in the desired direction.

Given the above, one can make the main conclusion about the need to review the system of working with patients not on the level of medical prevention but at the level of reviving the centers of preventive medicine, creating a united dynamic register of patients with $\mathrm{AH}$, considering all three units of chronic non-infectious diseases prevention. Existing centers of medical prevention in their work are focused only on primary prevention of diseases, and it is necessary to create cardiological dispensaries that are targeted not only on treatment of patients with $\mathrm{AH} / \mathrm{CHD}$, but also on risk factors prevention.

\section{Disclosures}

All authors have not disclosed potential conflicts of interest regarding the content of this paper. The research was made in the frame of the work plan of Post Diploma Education and Polyclinic Therapy of NovSU and budget financing of city treatment and prevention institutions.

\section{References}

[1] Yeganyan RA, Kalinina AM, Lachman EU, Izmailova OV, Shaternikova IN. Awareness and attitude to health among persons with mild or moderate. Disease prevention and health promotion. 2006; 1: 12-18. In Russian.

[2] Konradi AO, Polunicheva EV. Insufficient adherence to treatment of arterial hypertension: causes and correction methods. Arterial'naya Gipertenziya = Arterial Hypertension. 2004; 10(9): 21-29. In Russian.

[3] Pogosova GV, Belova YuS, Roslavtseva AN. Adherence to treatment in arterial hypertension and CHD as a key element in the reduction of cardiovascular mortality. Cardiovascular Theory and Profile. 2007, 6, 1, 99-104. In Russian.
[4] Kobalava Zh. D., Kotovskaya U. V., Sklizskova L. A, Karpov R. C., Nekrutenko L. A., Lopatin U. M, Filipenko N. G., Aseeva O. A. The perception of arterial hypertension in the elderly and real clinical practice in Russia (Results of phase I of "Argus", Russian scientific and practical programme). Cardiology. 2001; №11:14-20. In Russian.

[5] Oganov RG, Maslennikova GYa. Prevention of cardiovascular and other non-communicable diseases as the basis for improving the demographic situation in Russia. Cardiovascular Theory and Profile. 2005;3(1):4-9. In Russian.

[6] Neutel JM, Smith DH. Improving patient compliance: a major goal in the management of hypertension. J Clin Hypertens. 2003; 5(2): 127-32.

[7] Sabate E. Adherence to long-term therapies: evidence for action. WHO, Geneva, 2003.

[8] Schroeder K, Fahey T, Ebrahin S. How can we improve adherence to blood pressure-lowering medication in ambulatory care? Systematic review of randomized controlled trials. Arch Intern Med. 2004; 164: 722-732.

[9] Youssef RM, Moubarak II. Patterns and determinants of treatment compliance among hypertensive patients. Eastern Mediterranean Health Journal. 2002;8 (4-5):579-92.

[10] Gafarov VV, Pak VA, Gagulin IV, Gafarova AV. Epidemiology and prevention of chronic non-communicable diseases for two decades and in the period of socio-economic crisis in Russia. Novosibirsk. 2000; 227-229. In Russian.

[11] Kornylieva I. V, Shalnova S. A, Ivanov K. I. Medical and social factors in forming "cardio-vascular" health. Disease Prevention and Health Promotion. 2004;4:3-6. In Russian.

[12] Shapiro IA, Kalinina AM. Preventive health care for patients with arterial hypertension in outpatient facilities and polyclinics of Khabarovsk Region: status and prospects. Cardiovascular Therapy and Prevention. 2002;1:16. In Russian.

[13] Yavelov IS, Gratsiansky NA. Russian register of acute coronary syndromes: treatment and hospital outcomes in acute coronary syndrome without ST segment elevation. Cardiology. 2003; 12: 23-36. In Russian.

[14] Anand SS, Razak F, Davis AD, Jacobs R, Vuksan V, Teo K et al. Social disadvantage and cardiovascular disease: development of an index and analysis of age, sex, and ethnicity effects. Int J Epidemiol. 2006;35(5):1239-45.

[15] Choinière R, Lafontaine $P$, Edwards AC. Distribution of cardiovascular disease risk factors by socioeconomic status among Canadian adults. CMAJ. 2000;162(9 Suppl):S13-24.

[16] Kabir Z, Bennett K, Shelley E, Unal B, Critchley JA, Capewell S. Comparing primary prevention with secondary prevention to explain decreasing coronary heart disease death rates in Ireland. 1985-2000. BMC Public Health. 2007; 7: 117.

[17] Pogosova GV, Fishman BB, Melik-Ogandzanyan GYu, Bespalov EI, Kulikova TV. "RELIEF-Regular Treatment and Prevention" as a key to improving situation with cardiovascular diseases in Russia: Results of the Russian Multicentre Study (Research Survey). Clinical Medicine. Clinic, diagnosis, prevention and treatment. Interuniversity collection of CIS countries. Veliky Novgorod. Almaty. 2009; 17: 198-215. 
[18] Andrushenko AV, Drobizhev MU, Dobrovolsky AV. Comparative evaluation of CES-D, BDI and HADS (d) scales in diagnosing depression in medical practice. Neurology and Psychiatry Journal. 2003;5:11-17. In Russian.

[19] Chazov EI, Oganov RG, Pogosova GV, Shalnova SA, Romasenko LV, Deyev AD. Clinical and epidemiological depression study programme in cardiac practice: in patients with arterial hypertension and coronary heart disease (COORDINATE). Results of multicenter study. Cardiology. 2007; 47(3): 28-37. In Russian.
[20] Dimsdale JE. Symptoms of anxiety and depression as precursors to hypertension. JAMA. 1997; 277(7):574-5.

[21] Zigmond, AS; Snaith, RP (1983). "The hospital anxiety and depression scale". Acta Psychiatrica Scandinavica. 67 (6): 361-370. doi:10.1111/j.1600-0447.1983.tb09716.x. PMID 